\title{
RESEARCH OF THE INFLUenCe OF FLUe Gas PARAMETER ChANGeS ON AIR DisPersion ProcesSeS OF HAZARDOUS SUBSTANCES
}

\author{
Ionkin Igor ${ }^{\mathrm{a}}$, Ragutkin Aleksandra ${ }^{\mathrm{a}}$, Roslyakov Pavel ${ }^{\mathrm{b}}$, \\ Morozov Igor ${ }^{\mathrm{b}}$, Zaichenko Mikhail ${ }^{\mathrm{a}}$ \\ ${ }^{a}$ Moscow State University of Information Technologies, Radioengineering and Electronic, \\ s Vernadskiy prospekt 78, ${ }^{b}$ Moscow, 119454, Russia \\ National Research University «Moscow Power Engineering Institute», Krasnokarazmennaya street 14, \\ Moscow, 111250, Russia
}

\begin{abstract}
The article describes a promising technology of flue gas heat recovery for natural gas-powered boilers and presents the result of calculating air dispersion of hazardous emissions from chimney stacks on specific power plants. Following power plants were chosen for computational research: MPEI CHPP (Moscow) and peak-backup power plant PRK (Tomsk). The paper concludes that prior to the installation of condenser units preliminary computation of hazardous emissions dispersion is needed.
\end{abstract}

Keyword: hazardous substances; air dispersion processes; combustion products; fossil fuels, condenser unit; CHPP
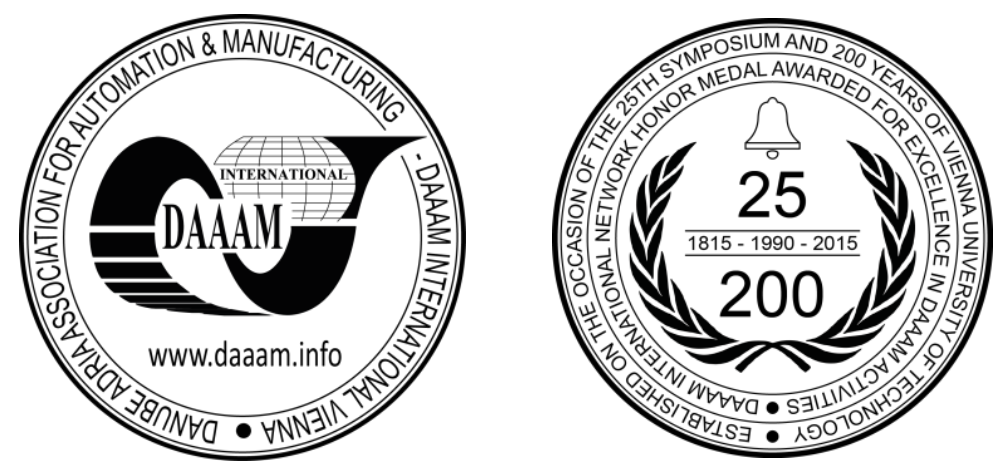

This Publication has to be referred as: Ionkin, I[gor]; Ragutkin, A[leksandr]; Roslyakov, P[avel]; Morozov, I[gor] \& Zaichenko, M[ikhail] (2016). Research of the Influence of Flue Gas Parameter Changes on Air Dispersion Processes of Hazardous Substances, Proceedings of the 26th DAAAM International Symposium, pp.0378-0384, B. Katalinic (Ed.), Published by DAAAM International, ISBN 978-3-902734-07-5, ISSN 1726-9679, Vienna, Austria

DOI:10.2507/26th.daaam.proceedings.051 


\section{Introduction}

Combustion products of organic fuels that are released into the atmosphere contain hazardous substances, and lots of research all over the world is devoted to decreasing these emissions. Such research papers study the problem of reducing the concentration of the hazardous substances [1,2] and increasing equipment efficiency [3-5]. One important aspect of industrial impact on the environment is the air dispersion of produced hazardous substances using chimney stacks, which enables lower their ground-level concentration. Dispersion is further improved by high temperature of the flue gases and installation of high stacks.

\section{Technology overview}

One of the efficient energy saving technologies is the recovery of the low-grade flue gas heat. Condensing heat recovery units (condensers) are widely used for this task in the Northern Europe. Such condensers are economically feasible when burning fuels with high vapor content in combustion products, such as natural gas or wood chips. Despite the fact that the share of natural gas in the Russian fuel balance amounts to approximately $70 \%$, condensers are not yet widely spread. However, as gas prices grow the demand for condensers will increase significantly.

After the installation of such condenser units power plants do not release the flue gas with the temperature of $120-170^{\circ} \mathrm{C}$ directly from the boiler into the atmosphere, but direct the flue gas into the condenser, where it is cooled to $30-50^{\circ} \mathrm{C}$, which is below the dew point of water vapor. During this process additional heat is generated in the condenser both due to the cooling down of flue gas and due to the partial condensation of water vapor contained in it. This heat can be delivered to the consumer, most frequently into the district network. In Russia the temperature of return district water is quite high and can reach $50-60^{\circ} \mathrm{C}$ (which is close to or even above the dew point). Therefore, the efficiency of flue gas heat recovery can be increased by using preheating by $20-50{ }^{\circ} \mathrm{C}$ and humidification of the outdoor air delivered to the burners in the boiler 6 .

The schematics of such a condensing heat recovery unit are given in Fig. 1. After the boiler the flue gas is delivered to the pre-cooler 1 , where it is cooled down to $70-80^{\circ} \mathrm{C}$ (hereinafter temperature figures are approximate, precise temperature depends both on the construction and the performance conditions of the condenser). After this the flue gas is directed into the counter-flow contact heat exchanger (condenser) 2, passes through the plastic separator 3. The separator is washed with circulation water that is delivered from the above via a distribution device 4 . After this in the separator 5 the water drops are removed from the flue gas flow and the flue gas is directed into the stack. The circulation water heated in the condenser to $60^{\circ} \mathrm{C}$ transfers the heat to the return district water in the heat exchanger 6 . After this the cooled circulation water goes to the humidifier 7. The construction of the humidifier is similar to that of the condenser, and in it the circulation water heats and humidifies the outdoor air that is supplied into the boiler. As a result, the circulation water temperature is reduced to $41^{\circ} \mathrm{C}$, after which it is directed into the condenser. Since its temperature is lower than behind the heat exchanger 6 , this provides increased efficiency of the whole condenser unit. Excess condensate is removed into the neutralization tank 8 [1].

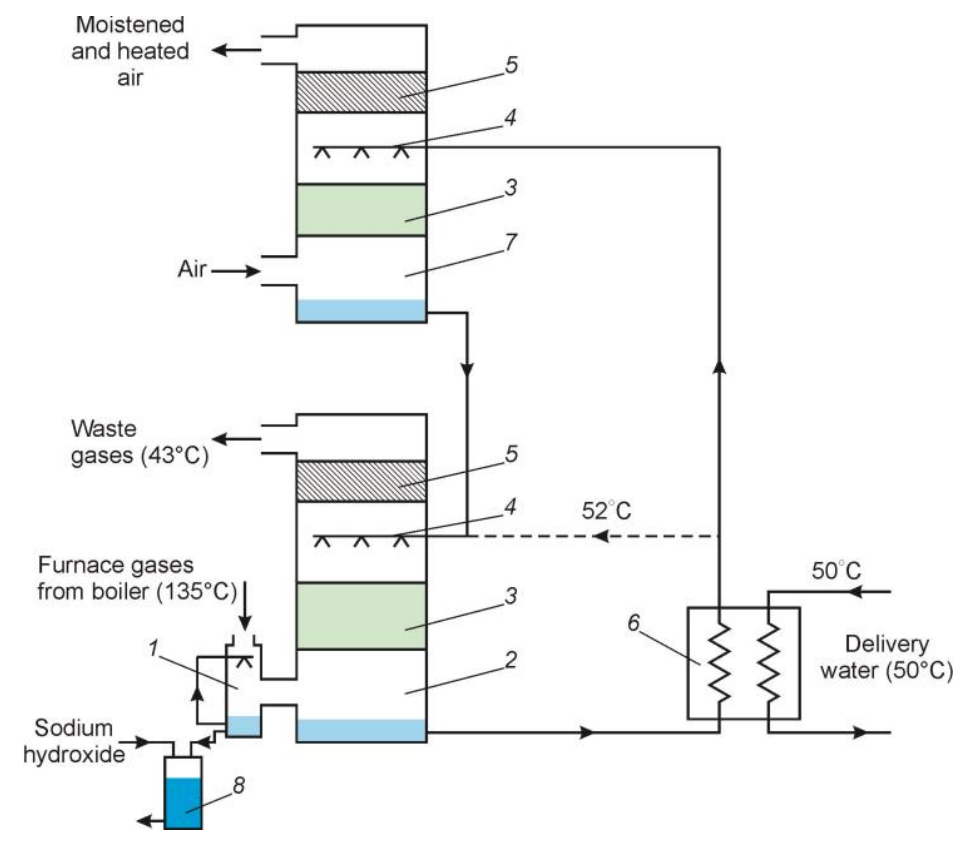

Fig. 1. Schematics of the condensing heat recovery unit

Installation of a condenser on a CHPP or a boiler changes the parameters of the flue gas released into the atmosphere: its volume, temperature and humidity are significantly decreased. If the design with pre-heating and prehumidification of combustion air is implemented, the temperature and content of combustion products are changed, 
which leads to the changes in superheater [7] operation. This also results in 40-60\% reduction in the content of the main toxic component of natural gas combustion products - nitrogen oxides by means of reduced thermal NOX generation [8-10]. It is worth mentioning that after the condenser unit the combustion products can be released into the atmosphere both via the existing stack and via an additionally installed (usually 40-60 m high) stack made of plastic or stainless steel. This is conditioned by the increased probability of water vapor condensation on the stack walls due to the low temperature of the flue gas behind the condenser. All these factors affect the air dispersion of combustion products. In this respect, one of the important tasks while designing condenser units is the evaluation how the above mentioned factors will influence the changes in the ground-level concentration of hazardous substances.

\section{Theory}

With this task in mind the article researches the calculations of the condenser technology effect on the air dispersion of flue gas in the impact area of energy objects. This was achieved using calculation method that makes it possible to establish the ground-level concentration of various substances based on known parameters of the emission point, theoretical and empiric preconditions. Calculation of ground-level concentrations uses not only the data on massive emission, but also such information as meteorological parameters of the atmosphere, geometric characteristics of the emission source and the surrounding site that affect the process of dispersion of studied substances.

The calculation was performed using the Ekolog unified software for calculating air pollution, that implements the applied in Russia OND-86 [11] method of calculating hazardous substances concentration in the atmosphere.

Following data is needed to calculate the air dispersion:

- Type and geometric dimensions of the emission source;

- Characteristics of combustion products;

- Dimensions and location of buildings on the surrounding site;

- Weather conditions with constant meteorological characteristics.

Dispersion of pollutants in the atmosphere is influenced by such parameters as wind speed, air temperature, height allocation and also the combination of parameters that affect the turbulence diffusivity coefficient. Such parameters can include: air humidity, atmospheric radiation index, time of day, type of ground surface etc. The calculations were performed for the least favorable weather conditions .

Since the main toxic component of the natural gas combustion is NOX (massive emission of which was recalculated to $\mathrm{NO} 2$ ), following calculation parameters were used to evaluate the effect of the condenser unit on the air dispersion:

- $\quad$ maximum value of ground-level NO2 concentration in the adjacent area;

- concentration pattern of NO2 in the adjacent area;

- pattern of maximum ground-level NO2 concentrations that were reached when the non favorable dispersion conditions and air speed were combined.

$\mathrm{T}$ he calculation considered only the emissions from the studied emission sources, i.e. it did not include the background concentrations. Following power plants were evaluated:

- $\quad$ MPEI educational-experimental CHPP (Moscow, Lefortovo district);

- $\quad$ Peak-backup power plant (Tomsk).

\section{Evaluation of combustion products dispersion in the area adjacent to MPEI educational-experimental CHPP}

Chimney stacks of the MPEI CHPP are located directly on the building of the CHPP boiler house (Fig. 2). The stacks are made of metal and are relatively short. Mouth of the stack are located $50 \mathrm{~m}$ above the ground. Diameter of the mouth is $1.5 \mathrm{~m}$. Since only one BM-35RF boiler is running at the moment, only one stack is the emission source.

The speed of flue gas exit to the atmosphere is conditioned by its volume flow rate and the diameter of the stack mouth. The calculations assumed that the flue gas flow escapes the stack directly vertically without any spin. During the calculations it was suggested that when the condenser unit is running the whole volume of flue gas is emitted through the additional stack with the height of $50 \mathrm{~m}$ (Fig. 2b). 

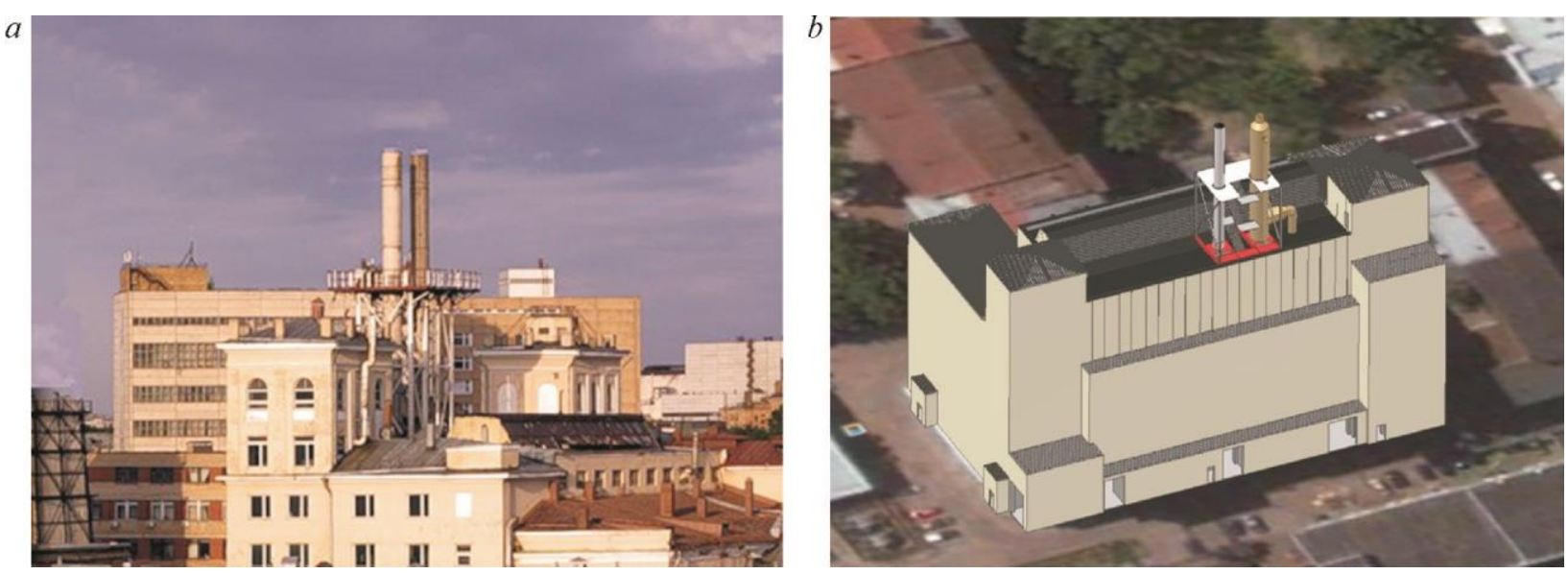

Fig. 2. MPEI CHPP stacks: (a) - initial variant; (b) design with the condenser unit

The assumption based on experimental data was that after the installation of the condenser unit the volume of NOX emissions will reduce by $50 \%$. The input data for the calculation is provided in Table. 1 .

\begin{tabular}{lll}
\hline Parameter & Initial variant & $\begin{array}{l}\text { Variant with the } \\
\text { condenser unit }\end{array}$ \\
\hline Stack height, $\mathrm{m}$ & 50 & 50 \\
Mouth diameter, $\mathrm{m}$ & 1,5 & 1 \\
Volume flow rate of combustion products, $\mathrm{nm}^{3} / \mathrm{s}$ & 13,45 & 11,96 \\
Combustion products temperature, ${ }^{\circ} \mathrm{C}$ & 130 & 45 \\
Combustion products velocity in the stack mouth, $\mathrm{m} / \mathrm{s}$ & 11,24 & 17,75 \\
Massive emission of nitrogen oxides, $\mathrm{g} / \mathrm{s}$ & 2,35 & 1,17 \\
\hline
\end{tabular}

Table 1. Input data for the calculation

The map of the Lefortovo district in the correct scale is included into the picture. Fig. 3 demonstrates the calculation results for the air dispersion of nitrogen dioxide, taking into account the buildings in the area respectively for the initial variant and the variant with the condenser unit, with the predominating wind direction for this district.

It should be noted that the dispersion process is influenced by two factors with opposite effect - reduction of flue gas temperature and the decrease in $\mathrm{NO}_{\mathrm{x}}$ emission volume. This resulted in the fact that the installation of the condenser unit had almost no influence on the maximum ground-level $\mathrm{NO}_{2}$ concentrations. The pattern of areas with different concentrations changed - maximum amounts are registered closer to the emission source and cover slightly larger area due to worse dispersion. However, in the rest of the territory the concentration of nitrogen oxides is notably reduced due to the decrease of its emitted volume.
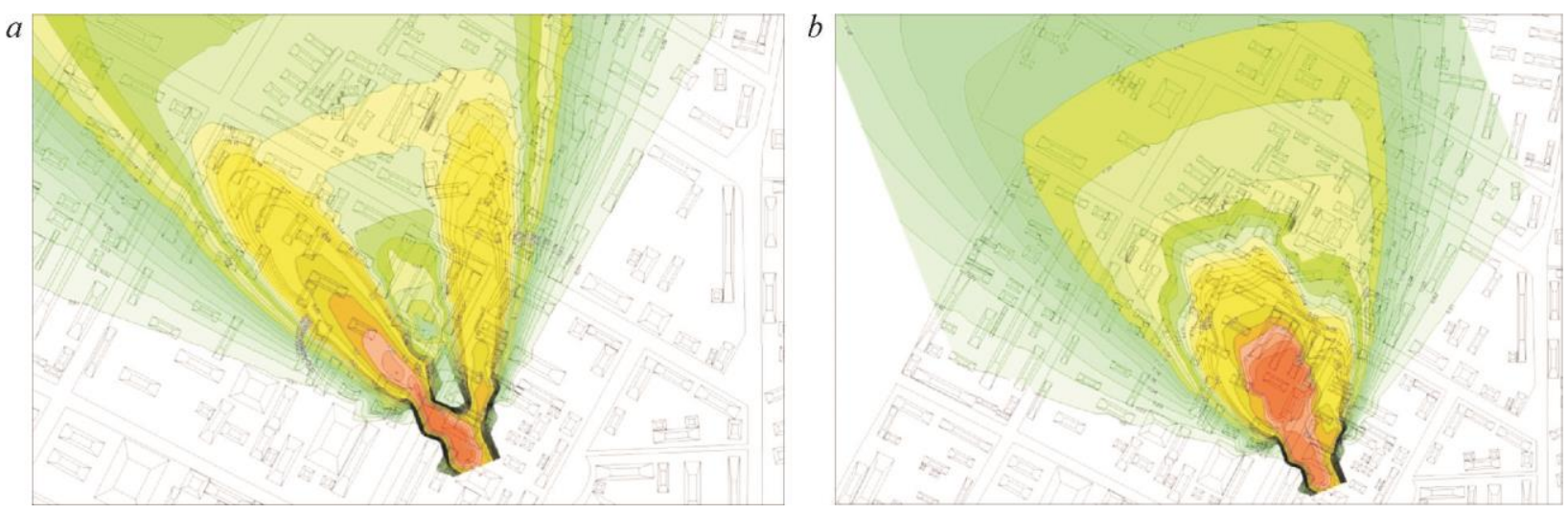

Fig. 3. Dispersion of NO2 from MPEI CHPP stacks: (a) without the condenser unit; (b) with the condenser unit

Fig. 4 depicts the pattern of maximum ground-level NO2 concentration in the area adjacent to MPEI CHPP with all possible combinations of wind speed and directions respectively for the initial variant and the condenser unit variant. 


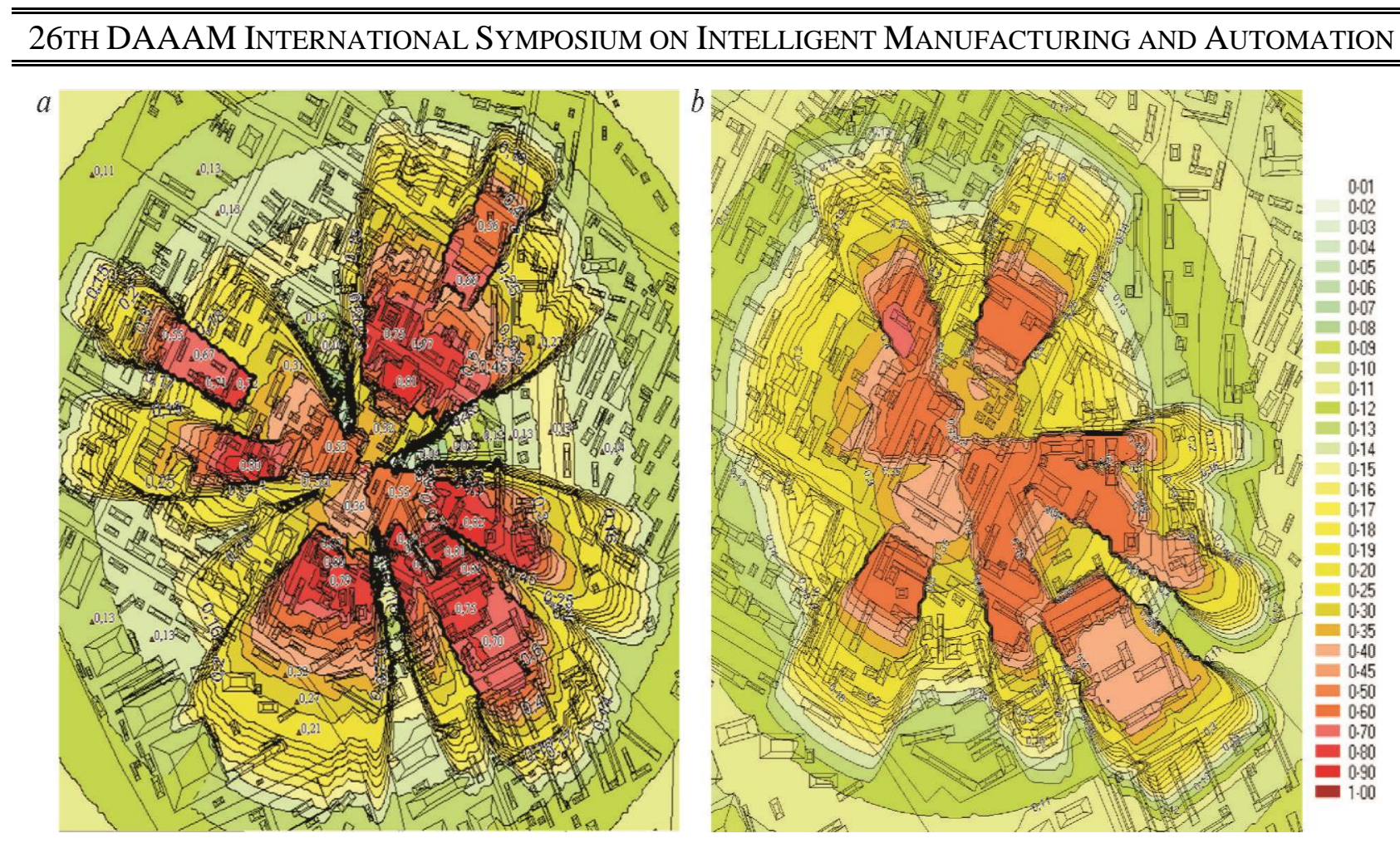

Fig. 4. Dispersion of $\mathrm{NO}_{2}$ from MPEI CHPP stacks with all possible combinations of wind speed and directions: (a) without the condenser unit; (b) with the condenser unit

The figures clearly depict the areas with increased values of ground-level $\mathrm{NO}_{2}$ concentrations. They are highlighted with bright red color. These areas are formed because of the high buildings that prevent dispersion. The calculations show that the reduction of $\mathrm{NO}_{\mathrm{X}}$ emission volume will result in the decrease of maximum ground-level $\mathrm{NO}_{2}$ concentration in the area adjacent to MPEI CHPP from 0.81 to 0.54 of the maximum permissible concentration level.

It can be concluded that if flue gas after the condenser unit is emitted into the atmosphere via a stack of same height as before the installation, this will ensure the reduction of ground-level concentration of $\mathrm{NO}_{2}$ in the adjacent area. This is conditioned by the reduction of $\mathrm{NO}_{\mathrm{x}}$ emission as the result of condenser unit operation.

\section{Evaluation of combustion products dispersion in the area adjacent to the peak-backup power plant in Tomsk}

The existing stack of the peak-backup power plant is located close to the boiler house building (Fig. 5).
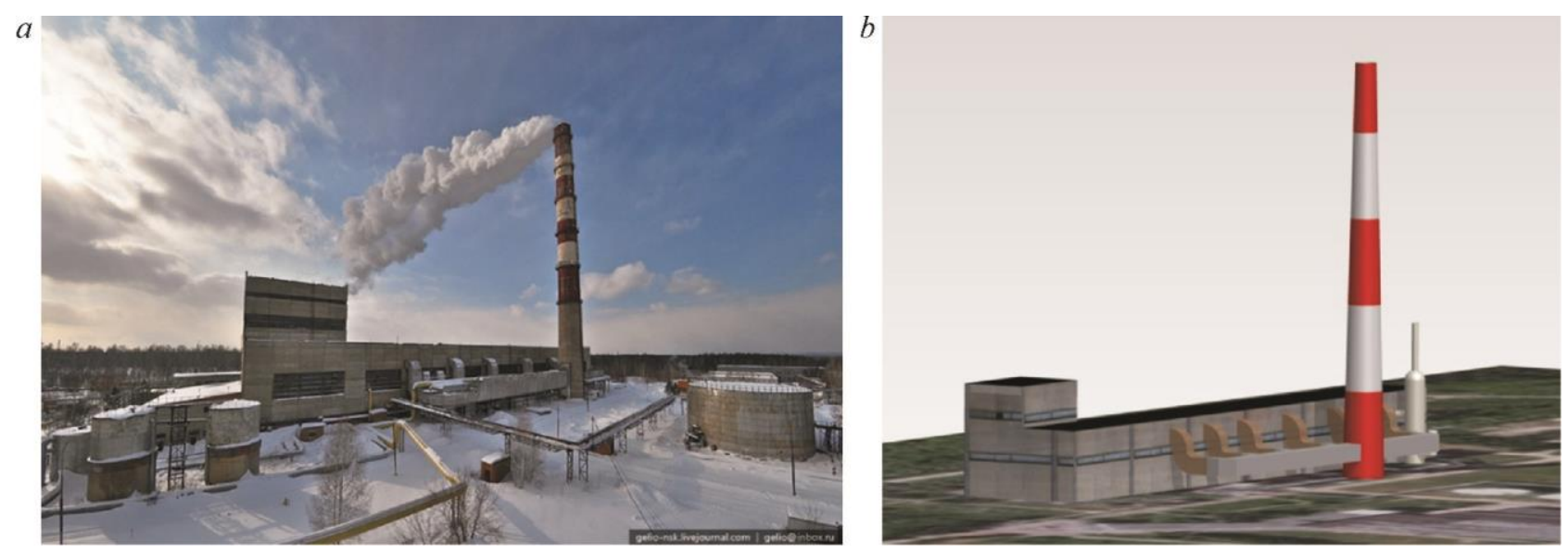

Fig. 5. Peak-backup power plant stacks: (a) - initial variant; (b) design with the condenser unit

The stack is a reinforced-concrete shaft with inner brick lining. It is supposed that if the condenser unit is installed on the PTVM-180 boiler the combustion products after the condenser will be directed into an additional plastic stack (Fig. 5b), and the flue gas from other operational boilers into the existing chimney.

Volume flow rate of combustion products was calculated for the average load of the peak-backup power plant. The initial data for the calculation are given in Table 2. 


\begin{tabular}{llll}
\hline Parameter & Initial variant & $\begin{array}{l}\text { Variant with the condenser unit (columns } \\
\text { for the main and additional stack) }\end{array}$ \\
\hline Stack height, $\mathrm{m}$ & 50 & 120 & 42 \\
Mouth diameter, $\mathrm{m}$ & 1,5 & 6,5 & 2,4 \\
Volume flow rate of combustion products, $\mathrm{nm}^{3} / \mathrm{s}$ & 13,45 & 57,6 & 76,8 \\
Combustion products temperature, ${ }^{\circ} \mathrm{C}$ & 130 & 130 & 45 \\
Combustion products velocity in the stack mouth, $\mathrm{m} / \mathrm{s}$ & 11,24 & 2,56 & 19,78 \\
Massive emission of nitrogen oxides, $\mathrm{g} / \mathrm{s}$ & 2,35 & 31,4 & 15,7 \\
\hline
\end{tabular}

Table 2. Initial data for the calculation

Calculation results are provided in Fig. 6-7.


Fig. 6. Dispersion of $\mathrm{NO}_{2}$ from peak-backup power plant: (a) without the condenser unit; (b) with the condenser unit
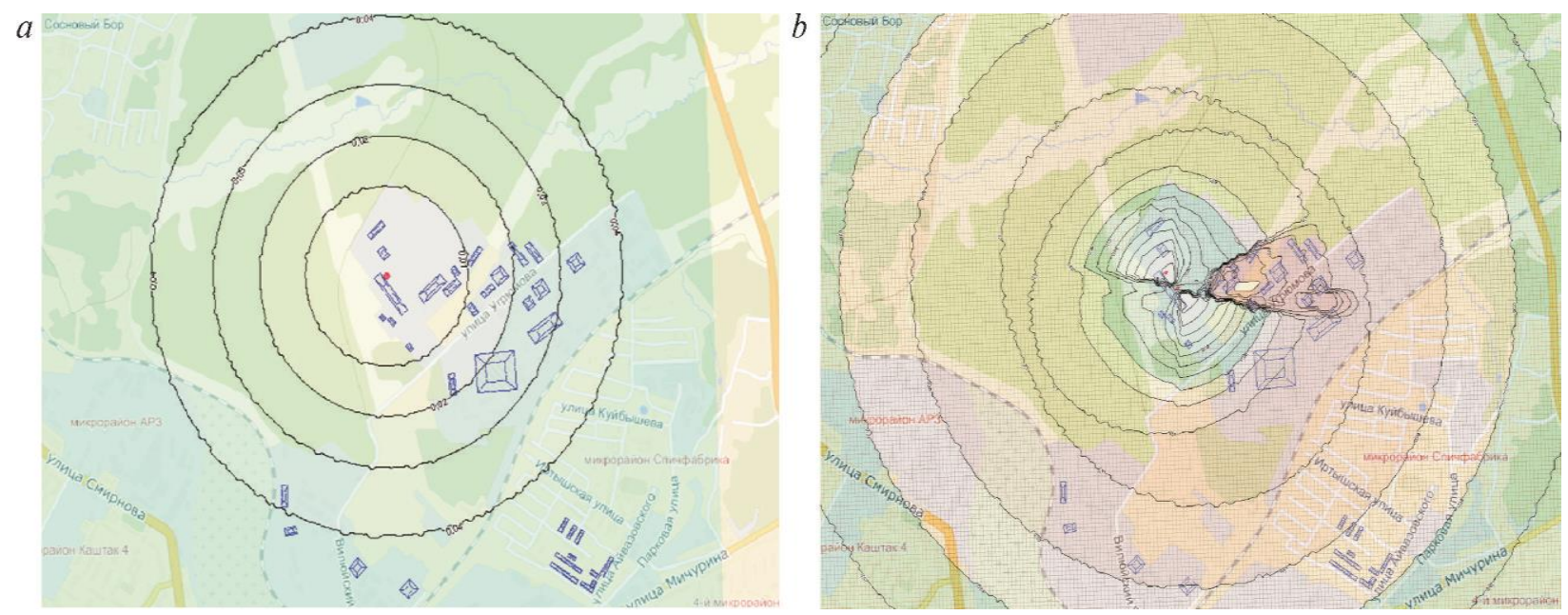

Fig. 7. Dispersion of $\mathrm{NO}_{2}$ from peak-backup power plant stacks with all possible combinations of wind speed and directions: (a) without the condenser unit; (b) with the condenser unit

It should be noted that the existing stack of the peak-backup power plant is considerably high, and there are no high buildings in the surrounding area. This conditions significant difference in the pattern of different concentration zones compared to MPEI CHPP.

Due to the smaller height of the additional stack the dispersion near the emission source will be worse, and maximum concentrations will increase significantly after the installation of the condenser. However, the maximum concentration of nitrogen dioxide will not exceed 0.3 of the maximum permissible concentration level.

It can be concluded that the total amount of NOx emission will be reduced as the result of condenser unit operation. However, smaller height of the additional stack will lead to the increase of ground-level concentration in the area directly adjacent to the emission source. 


\section{Conclusion}

Installation of a condenser unit results in the changes in the air dispersion of flue gases in the adjacent area. The conducted research shows that if the flue gas after the condenser unit is emitted into the atmosphere via a stack of smaller height, the ground-level concentration of pollutants in the area directly adjacent to the emission source can significantly increase even despite the overall reduction of hazardous emissions. Consequently, when designing condenser units the decision to use an additional stack and choice of stack parameters should be justified by the calculations of air dispersion. In the future it is planned to undertake a study and search for solutions to direct the flue gas after the condenser unit into existing stacks without impairing stack performance.

\section{Acknowledgments}

The work was supported by the Federal Task Program «Research and development in foreground directions of the development of the scientific and technical complex of Russia for 2014-2020» (project no. RFMEFI57714X0147).

\section{References}

[1] Hyerim Gu, Kwang Min Chun, Soonho Song, The effects of hydrogen on the efficiency of NOx reduction via hydrocarbon-selective catalytic reduction (HC-SCR) at low temperature using various reductants, International Journal of Hydrogen Energy, 2015 vol. 40, issue 30, pp. 9602-9610.

[2] Sandro Dal Secco, Olivier Juan, Myriam Louis-Louisy, Jean-Yves Lucas, Pierre Plion, Lynda Porcheron, Using a genetic algorithm and CFD to identify low NOx configurations in an industrial boiler, Fuel, Elsevier, 2015 , vol. 158, pp. 672-683.

[3] P.V.Roslyakov, I.L. Ionkin,K.A. Pleshanov, The optimal conditions for firing fuel with controlled incomplete combustion, Thermal Engineering,Pleiades Publishing Ltd., 2010, vol. 57, issue 4, pp. 290-295.

[4] S. Laux, J. Grusha, The benefits of coal/air flow measurement and control on NOx emission and boiler performance, Foster Wheeler Power Group, Powergen Europe, Dusseldorf, Germany, 2003.

[5] Sen Li, Tongmo Xu, Shien Hui, Xiaolin Wei, NOx emission and thermal efficiency of a 300 MWe utility boiler retrofitted by air staging, Applied Energy, Elsevier, 2009, vol. 86, issue 9, pp. 1797-1803.

[6] I.L. Ionkin, A.V. Ragutkin, P.V. Roslyakov, V.M. Supranov, M.N. Zaichenko and B. Luning, Effect of a Condensation Utilizer on the Operation of Steam and Hot Water Gas Fired Boilers, Thermal Engineering, Pleiades Publishing Ltd., 2015, vol. 62, No. 5, pp. 352-358.

[7] T. Nahlovsky,Optimization of Fuzzy Controller Parameters for the Temperature Control of Superheated Steam, Annals of DAAAM and Proceedings of the International DAAAM Symposium, 2014, pp. 1547-1555.

[8] Kormilitsyn, V.I., Lyskov, M.G., Novikov, V.M., Kudryatsev, N.Yu., Suppressing nitrogen oxides by spraying water into the combustion zone of a boiler furnace, Thermal Engineering, Pleiades Publishing Ltd., 1990, vol. 37, issue 10, pp. 549-553.

[9] P.V. Roslyakov, Effect of water injection on thermal and fuel nitrogen oxides emissions, Proceedings of the universities, Energy, 1988. No 7. pp. 59-64 (in Russian).

[10] P.V.Roslyakov, K.A. Pleshanov, I.L. Ionkin, Fuelcombustionwithmonitoredmoderateunderburning (ConferencePaper) Source of the Document Annals of DAAAM and Proceedings of the International DAAAM Symposium, 2011, pp. 1153-1154.

[11] RD 52.04.212-86 (OND-86), Method for calculating of concentrationsof theharmful substances in the plant air emissions, 1987, Gidrometeoizdat, Leningrad, (in Russian). 